\title{
SYMBIOTIC DIVERSITY AMONG ACID-TOLERANT BRADYRHIZOBIAL ISOLATES WITH COWPEA
}

\author{
C. Appunu ${ }^{1}$, L. M. L. Reddy ${ }^{2}$, C. V. C. M. Reddy ${ }^{2}$, D. $\operatorname{Sen}^{2}$ and B. $\operatorname{Dhar}^{2}$
}

\begin{abstract}
A total of eight acid tolerant strains of bradyrhizobia isolates from indigenous cowpea plants grown in acid soil in Varanasi, Uttar Pradesh, India, were examined for their ability to survive in soil and yeast extract mannitol broth at low pH levels. All these isolates survived in acidic (pH 3.5-6.5) conditions. Survival capacity of rhizobia was higher in soil than in nutrient medium at low pH 3.5-6.5 levels. Symbiotic effectiveness of these strains under polyhouse conditions in sterilized soil of $\mathrm{pH} 4.5$ recorded the highest and lowest symbiotic characters for dry matter production and nitrogen improvement per plant in CR09 and CR2O inoculated plants, respectively. All the examined isolates showed variability in their symbiotic performances. The strain found to be more tolerant to stress were more effective $\mathrm{N}_{2}$ fixers in symbiosis with cowpea cv. Paiyurl under acid-soil conditions. Symbiotic variation among different strains showed that there is potential to improve strain performance under stress conditions.
\end{abstract}

Key words: Acid tolerant, bradyrhizobia, cowpea, symbiotic effectiveness.

\section{INTRODUCTION}

In India, cowpea (Vigna unguiculata L. Walp) is cultivated by commercial and subsistence farmers. They provide a valuable source of protein and thereby sustaining the nutritional balances of low income populations (Singh et al., 1997) and also help in maintaining soil health through biological nitrogen fixation by symbiotic rhizobia. Cowpea depends on their symbionts for a large part of their nitrogen requirements for growth and dry matter production. The cowpea symbionts are classified into slow-growers, Bradyrhizobium spp. and fast-growers, Sinorhizobium spp. (Zhang et al., 2007). Selected symbiotically efficient rhizobia were used as inoculants to increase biologically fixed $\mathrm{N}_{2}$ under field conditions. The introduced strain must compete with highly adapted indigenous rhizobia for legume nodulation under specific physiological and biological soil conditions. Many biotic and abiotic factors affect the persistence of symbiotically effective introduced rhizobial strain in soil. Soil acidity is the one of the factors which restricts production of cowpea through its impact on nitrogen fixation. The failure of nodulation under acid soil conditions is common, especially in soils of $\mathrm{pH}$ less than 5. Soil acidity limits symbiotic nitrogen fixation by limiting Rhizobium survival and persistence in soils, as well as reducing nodulation (Ibekwe et al., 1997). High symbiotic effective rhizobial inoculation is a common practice in agricultural legume production (Catroux et $a l ., 2001)$ which requires survival and establishment of inoculated rhizobia in the soil environment (Da and Deng, 2003). There is no history of inoculation of acid tolerant strains in acidic soil in India. A wide variation in the tolerance to acid-soil conditions have been reported among Bradyrhizobium strains of many agriculturally important legumes from

${ }^{1}$ Section of Plant Breeding ,Division of Crop Improvement, Sugarcane Breeding Institute,Coimbatore- 641 007,Tamil Nadu, India.

${ }^{2}$ Microbial Genetics Laboratory, Department of Genetics and Plant Breeding, Institute of Agricultural Science, Banara Hindu University, Varanasi-221005, India. 
various countries (Ayanaba et al., 1983; Graham et al., 1994; van Rossum et al., 1994; Raza et al., 2001) and in India (Appunu et al., 2005). Keeping in view the role of acid-tolerant strain, we report here the survival of bradyrhizobial isolates in acidic conditions and their symbiotic effectiveness with cowpea.

\section{MATERIALS AND METHODS}

\section{Bradyrhizobial Isolates}

Eight acid tolerant bradyrhizobia strains, CR01, CR05, CR07, CR09, CR12, CR15, CR18 and CR20 were isolated from nodules of indigenous cowpea plants grown in acid soil by following the method of Vincent (1970) and were used in the experiments. All strains were maintained on yeast extract mannitol (YEM) medium and transferred to fresh slant every month.

\section{Growth of bradyrhizobial isolates at low pH levels}

Soil $\mathrm{pH}$ was estimated by suspending $40 \mathrm{~g}$ of air dried soil in $100 \mathrm{ml}$ distilled water, after allowing the suspension to stand for 1 $\mathrm{h}$ at room temperature. Soil sample and yeast extract mannitol broth were sterilized in autoclave at $121^{\circ} \mathrm{C}$ for $15 \mathrm{~min}$ (JRIC39E, Osworld India). The $\mathrm{pH}$ level of the soil sample ( $\mathrm{pH} 4.5)$ and medium $(\mathrm{pH} 6.8)$ was modified to obtain the required $\mathrm{pH}$ values of $3.5,4.5,5.5$ and 6.5 by adding 1 $\mathrm{N} \mathrm{HCl}$ or $\mathrm{NaOH}$ and no changes in $\mathrm{pH}$ were observed after autoclaving. All the bradyrhizobia isolates were multiplied in YEM broth and $1 \mathrm{ml}$ of multiplied rhizobial culture (about $10^{8}$ rhizobial cells $/ \mathrm{ml}$ ) used as standard inoculum introduced into soil mixture $(2.5 \mathrm{~g}$ of soil + $1 \mathrm{ml}$ of distilled water) and to YEM broth of low $\mathrm{pH}$ levels and YEM broth with $\mathrm{pH}$ 6.8 as control for comparison. Standard volume of inoculum also introduced in the YEM Flasks containing treated soil and YEM broth were kept on a rotary incubator shaker (200 rev. $\left.\mathrm{min}^{-1}\right)$ (ACM22064-I, ACMAS Technology India) at 28 $\pm 2^{\circ} \mathrm{C}$ for 7 days. The rhizobial growth was determined (cfu ml ${ }^{-1}$ ) by a plate count technique (Vincent, 1970) using YEM agar plates.

\section{Symbiotic efficiency of rhizobial isolates}

Genetically pure and healthy seeds of cowpea cv. Paiyur1 were surface sterilized as explained by Appunu et al. (2005). In brief, seeds were surface-sterilized with acidified mercuric chloride $(0.2 \% \mathrm{w} / \mathrm{v})$ for 3-5 minutes and 70\% ethyl alcohol for 1-2 minutes and then thoroughly rinsed with sterile distilled water for 4-5 times. Sterilized seeds were coated with bradyrhizobia as detailed by Vincent (1970). The untreated seeds were served as control. Seeds were grown in earthern pots containing sterilized soil [pH 4.5; organic carbon (0.78); CEC (11.8 cmol (+) $\left.\mathrm{Kg}^{-1}\right)$; EC $\left(<0.23 \mathrm{dSm}^{-1}\right)$; exchangeable $\mathrm{Al}(\mathrm{cmol}$ (+) $\left.\mathrm{Kg}^{-1}\right)$; total $\left.\mathrm{N}(0.10)\right]$ under polyhouse conditions. Each pot was maintained with one healthy seedling. Each treatment was replicated five times. Plants were supplied with water at appropriate times and were maintained to grow till 5 weeks in polyhouse having adequate temperature 30-35 ${ }^{\circ} \mathrm{C}$, humidity $70-80 \%$ and light intensity 1,600-2000 lux. Plants were harvested after five weeks of sowing and data pertaining to symbiotic and vegetative characters were recorded as described previously (Appunu et al., 2005).

Data were subjected to analysis of variance, and means were classified using Duncan's multiple-range test at the 0.05 probability level.

\section{RESULTS AND DISCUSSION}

The bradyrhizobia isolates were characterized to their growth response to low levels of $\mathrm{pH} 3.5$ - 6.5. The results showed that these isolates were tolerant to extreme acidic conditions since they could survive and grew in the low $\mathrm{pH}$, even at 3.5 (Figures 1 and 2). The rhizobia population showed higher level of survival capacity in acid soils than in nutrient broth 
at low levels of $\mathrm{pH} 3.5-5.5$. It could be explained that attachment of rhizobial with cations/anions or organic molecules in the soil are one of the reasons for higher growth rate in soil than in nutrient broth. These results are in agreement with those reported earlier that Rhizobium strains which survived in the acid soil cannot grow on a nutrient medium with $\mathrm{pH}$ as low as that of the soil (Asanuma and Ayanaba, 1990). Rhizobial strains of a given species vary widely in their $\mathrm{pH}$ tolerance (Zahran et al., 1999; Appunu et al., 2005). The fast growing Rhizobium strains have generally been considered less tolerant to acid $\mathrm{pH}$ than slow growing strains of Bradyrhizobium (Graham et al., 1994). However, Mpepereki et al. (1997) reported that both fast- and slow-growing Bradyrhizobium strains of Vigna unguiculata are tolerant to $\mathrm{pH}$ values as low as 4.0. Rhizobia adopt various mechanisms to survive in the acid soil conditions (Zahran et al., 1999).

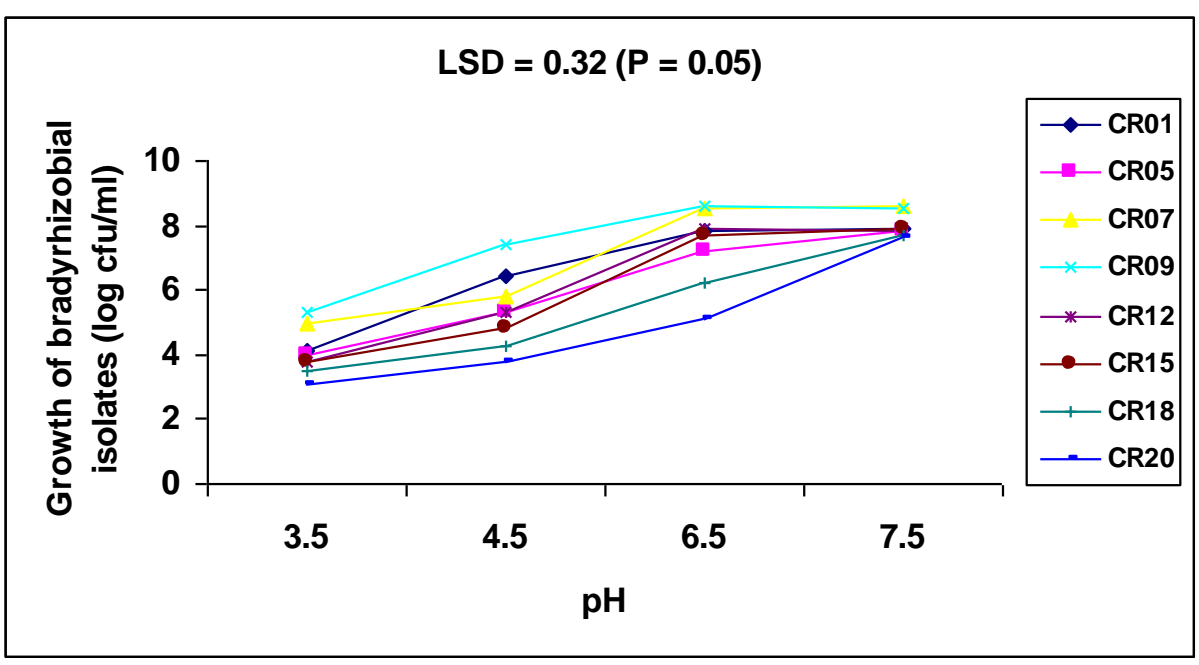

Figure 01: Effect of different level of acidic conditions (pH levels) on the growth of bradyrhizobial isolates of cowpea in soil.

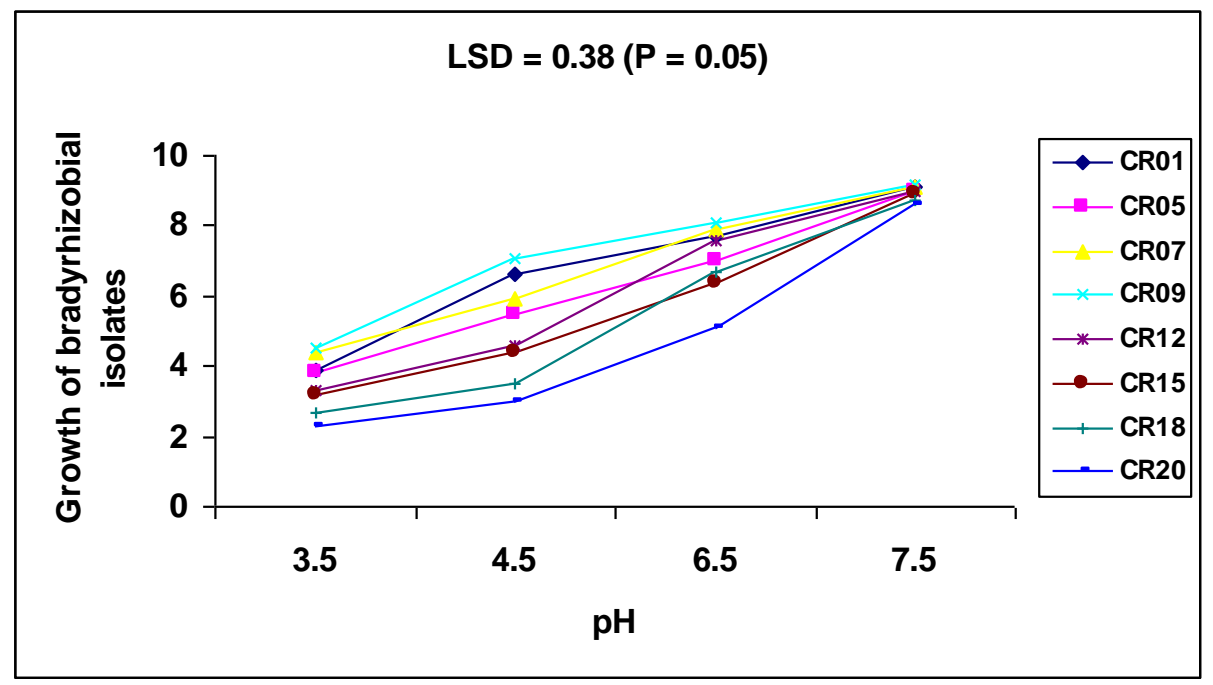

Figure 02: Effect of different level of acidic conditions (pH levels) on the growth of bradyrhizobial isolates of cowpea in yeast extract mannitol broth. 
The effect of inoculation of eight acid tolerant bradyrhizobia isolates on cowpea cv. Paiyur1 is presented in Table 1. All strains formed nodules and a significant variation was noticed in nodule number, dry weight and nitrogenase activity, dry matter production and nitrogen accumulation per plant. Highest nodule frequency, dry weight and nitrogenase activity were found in the plant inoculated with the strain CR09. However, inoculation of strains CR01, CR05, CR07, CR09 and CR12 also resulted in significantly high dry weight. In comparison to control, an increase of 5.74$39.08 \%$ in total plant dry weight was observed with strain inoculated treatments. Maximum enhancement in total plant dry matter $(39.08 \%)$ was noticed with the strain CR09, followed by CR07 (30.34\%), CR12 (28.04\%), CR05 (19.77\%) and CR01 (14.71\%). Percent increase of nitrogen content was also observed by the inoculation of strains. The highest nitrogen content $(2.40 \%)$ per plant was estimated in strain CR09 inoculated plants, while the lowest (1.90\%) was with CR18 and CR20 inoculated plants, which was 33.33 and $5.55 \%$ higher than that of control plants, respectively.

Table 01: Symbiotic effectiveness of acid-tolerant bradyrhizobial isolates on cowpea cv.

\section{Paiyur1}

\begin{tabular}{lllllll}
\hline Strain & $\begin{array}{l}\text { Total } \\
\text { no. of } \\
\text { nodules }\end{array}$ & $\begin{array}{l}\text { Dry weight } \\
\text { of nodules }\end{array}$ & $\begin{array}{l}\text { Nodules } \\
\text { nitrogenase activity } \\
\left(\mu \text { mol g }^{-1} \text { plant }^{-1}\right)\end{array}$ & $\begin{array}{l}\text { Total plant } \\
\text { dry matter } \\
\text { production }(\mathrm{g})\end{array}$ & $\begin{array}{l}\text { N } \\
\text { improvement } \\
\text { of plant }(\%)\end{array}$ \\
\hline CR01 & $27.21 \mathrm{c}$ & $0.19 \mathrm{~b}$ & $7.95 \mathrm{~b}$ & $4.99 \mathrm{~b}$ & 2.0 \\
$\mathrm{CR} 05$ & $32.03 \mathrm{~b}$ & $0.17 \mathrm{c}$ & $8.08 \mathrm{~b}$ & $5.21 \mathrm{~b}$ & 2.2 \\
CR07 & $34.10 \mathrm{~b}$ & $0.17 \mathrm{c}$ & $9.42 \mathrm{a}$ & $5.67 \mathrm{a}$ & 2.2 \\
CR09 & $48.54 \mathrm{a}$ & $0.22 \mathrm{a}$ & $10.36 \mathrm{a}$ & $6.05 \mathrm{a}$ & 2.4 \\
$\mathrm{CR} 12$ & $42.88 \mathrm{a}$ & $0.20 \mathrm{~b}$ & $9.76 \mathrm{a}$ & $5.57 \mathrm{a}$ & 2.3 \\
CR15 & $37.01 \mathrm{~b}$ & $0.23 \mathrm{a}$ & $7.91 \mathrm{~b}$ & $4.85 \mathrm{c}$ & 2.0 \\
CR18 & $22.32 \mathrm{~d}$ & $0.14 \mathrm{~d}$ & $4.96 \mathrm{c}$ & $4.73 \mathrm{c}$ & 1.9 \\
CR20 & $21.95 \mathrm{~d}$ & $0.11 \mathrm{e}$ & $4.41 \mathrm{c}$ & $4.55 \mathrm{c}$ & 1.9 \\
Control & $0.00 \mathrm{e}$ & $0.00 \mathrm{f}$ & $0.00 \mathrm{~d}$ & $4.35 \mathrm{c}$ & 1.8 \\
\hline
\end{tabular}

Those not followed by common superscript letters differ significantly at the LSD probability of $<0.05$

This study showed that inoculation of acid-tolerant isolates CR01, CR05, CR07, CR09 and CR12 leads to good nodulation, dry matter accumulation and improvement of nitrogen content cowpea. These isolates exhibited great diversity in their symbiotic performance and a few of them accumulated considerably high total plant dry weight and percent nitrogen content. Differential symbiotic performance of Bradyrhizobium isolates has already been reported (Zhang et al., 2002; Meghvanshi et al., 2005; Appunu et al., 2008). In most cases, $\mathrm{pH}$ sensitive stage in nodulation occurs early in the infection process and that Rhizobium attachment to root hairs is one of the stages affected by acidic conditions in soils. Only one of the symbionts needed to be acid tolerant for good nodulation to be achieved at $\mathrm{pH} 4.5$ (Vargas et al., 1988). van Rossum et al. (1994) reported that inoculation of acid 
tolerant Bradyrhizobium strains under acid-soil conditions improves the groundnut vegetative characters and yields. Selection of acid tolerant rhizobia to inoculate legume hosts under acid conditions will ensure the establishment of symbiosis and also successful performance (Correa and Barneix, 1997). However, the success or failure of inoculation depends on the competitive nodulation ability against indigenous bradyrhizobia under natural conditions. Graham (1992) and Carter et al. (1994) reported the existence of positive correlation between acid tolerance in laboratory and competitive nodulation on acidic soils.

\section{CONCLUTIONS}

In conclusion, four bradyrhizobia isolates CR07, CR09, CR01 and CR05 exhibited high growth at low $\mathrm{pH}$ levels and also showed better symbiotic performance in acid soils under laboratory conditions. These isolates could become useful inoculants in acid soils if they are superior in competitiveness under natural ecological conditions in the field.

\section{REFERENCES}

Appunu C, Sen D and Dhar B (2005). Acid and aluminium tolerance of Bradyrhizobium isolates from traditional soybean growing areas of India. Indian Journal of Agricultural Sciences 75(12),pp: 727-728.

Appunu C, Sen D, Singh MK and Dhar B (2008). Variation in symbiotic performance of Bradyrhizobium japonicum strains and soybean cultivars under field conditions. Journal of Central European Agriculture 9(1),pp: 185-190.

Asanuma S and Ayanaba A (1990). Variation in Acid-Al tolerance of Bradyrhizobium japonicum strains from African soils. Soil Science and Plant Nutrition 36(2),pp: 309318

Ayanaba A, Asanuma S and Munns DN (1983). An agar plate method for rapid screening of Rhizobium for tolerance to acid-aluminium stress. Soil Science Society of American Journal 47,pp: 256-268.

Carter JM, Gardner WK and Gibson AH (1994). Improved growth and yield of faba bean (Vicia faba cv. Fiord) by inoculation with strains of Rhizobium leguminosarum biovar viceae in acid soils in South-west Victoria. Australian Journal of Agricultural Research 45,pp: 613-623.

Catroux G, Hartmann A and Revellin C (2001). Trends in rhizobial inoculant production and use. Plant Soil 230,pp: 21-30.

Chauhan GS and Joshi OP (2005). Soybean (Glycine max) - the $21^{\text {st }}$ century crop. Indian Journal of Agricultural Sciences 75(8),pp: 461-469.

Correa OS and Barneix AJ (1997). Cellular mechanisms of $\mathrm{pH}$ tolerance in Rhizobium loti. World Journal of Microbiology and Biotechnology 13,pp: 153-157.

Da HN and Deng SP (2003). Survival and persistence of genetically modified Sinorhizobium meliloti in soil. Applied Soil Ecology 22,pp: 1-14.

Graham PH (1992). Stress tolerance in Rhizobium and Bradyrhizobium, and nodulation under adverse soil conditions. Canadian Journal of Microbiology 38,pp: 475-484.

Graham PH, Draeger K, Ferrey ML, Conroy MJ, Hammer BE, Martinez- Romero E, Naarons SR and Quinto C (1994). Acid $\mathrm{pH}$ tolerance in strains of Rhizobium and Bradyrhizobium, and initial studies on the basis for acid tolerance of Rhizobium tropici UMR1899. Canadian Journal of Microbiology 40,pp: 198-207. 
Ibekwe AM, Angle JS, Chaney RL and van Berkum P (1997). Enumeration and nitrogen fixation potential of Rhizobium leguminosarum biovar trifolii grown in soils with varying $\mathrm{pH}$ values and heavy metal concentrations. Agriculture Ecosystem and Environment 61,pp: 103-111.

Meghvanshi MK, Prasad K and Mahna SK (2005). Identification of $\mathrm{pH}$ tolerant Bradyrhizobium japonicum strains and their symbiotic effectiveness in soybean (Glycine $\max$ (L.) Merr.) in low nutrient soil. African Journal of Biotechnology 4(7),pp: 663-666.

Mpepereki S, Makonese F and Wollum AG (1997). Physiological characterization of indigenous rhizobial nodulation Vigna unguiculata in Zimbabwean soils. Symbiosis 22,pp: 275-292.

Raza S, Jornsgard B, Abou-Taleb H and Christiansen JL (2001). Tolerance of Bradyrhizobium sp. (Lupini) strains to salinity, $\mathrm{pH}, \mathrm{CaCO}_{3}$ and antibiotics. Letters in Applied Microbiology 32,pp: 379-383.

Singh BB, Mohan Raj DR, Dashiell KE and Jackai Len (1997). Advances in cowpea research. IITA-JIRCAS, Ibadan, Nigeria

van Rossum D, Muyotcha A, De Hope BM, van Verseveld HW, Stouthamer AH and Boogerd FC (1994). Soil acidity in relation to groundnut-Bradyrhizobium symbiotic performance. Plant Soil 163,pp: 165-175.

Vargas AAT and Graham PH (1988). Phaseolus vulgaris cultivar and Rhizobium strain variation in acid-pH tolerance and nodulation under acid conditions. Field Crops Research 19,pp: 91-101.

Vincent JM (1970). A manual for the practical study of the root nodule bacteria. The Blackwell Scientific Publications, Oxford.

Zhang H, Daoust F, Charles TC, Driscoll BT, Prithiviraj B and Smith DL (2002). Bradyrhizobium japonicum mutants allowing improved nodulation and nitrogen fixation of field grown soybean in a short season area. Journal of Agriculture Science 138,pp: 293-300.

Zhang WT, Yang JK, Yuan TY and Zhou JC (2007). Genetic diversity and phylogeny of indigenous rhizobia from cowpea [Vigna unguiculata (L.) Walp.]. Biology and Fertility of Soils 44,pp: 201-210

Zahran HH (1999). Rhizobium-legume symbiosis and nitrogen fixation under severe conditions and in an arid climate. Microbiology and Molecular Biology Reviews 63(4),pp: 968-989. 